\title{
Layered Coatings to Control Weight Loss and Preserve Gloss of Citrus Fruit
}

\author{
Robert D. Hagenmaier and Robert A. Baker \\ U.S. Department of Agriculture, Agricultural Research Service, Citrus \\ Subtropical Products Laboratory, 600 Avenue South, North West, Winter \\ Haven, FL 33883-1909
}

Additional index words. wax, microemulsion, gloss, ethanol, permeability, Citrus sinensis, Citrus paradisi

\begin{abstract}
Valencia oranges [Citrus sinensis (L.) Osbeck cv. Valencia] and Marsh grapefruit [Citrus paradisi Macf.] were treated with single or double layers of coating. In cases where two coatings were applied, the first coating was a moisture-barrier wax; the second was either polyethylene wax or a mixture of shellac and resin ester. The inner coating reduced weight loss, and the outer coating imparted gloss. Fruit gloss, as measured by reflectometer, decreased more rapidly during 1 week at $20 \mathrm{C}$ with a single glossy coating than with the same coating applied as a second layer over a wax-based first coating. For citrus fruit, using resin ester or shellac as a high-gloss second coating tended to overly restrict the exchange of $\mathrm{O}_{2}$ and $\mathrm{CO}_{2}$; however, two layers of wax did not.
\end{abstract}

The formulator of citrus coatings is confronted with the challenge of attaining high gloss, reducing fruit shrinkage, imparting resistance to moisture damage, and permitting passage of sufficient $\mathrm{CO}_{2}$ and $\mathrm{O}_{2}$ to prevent development of off-flavors (Kaplan, 1986).

Citrus coatings used by the packinghouse industry are not always successful in meeting these goals. Although freshly coated fruit achieves good gloss (Namesny and Pablo, 1988), the shrinkage rate of coated fruit is virtually the same as that of unwashed control fruit (Ben-Yehoshua, 1967; Hagenmaier and Baker, 1993a). Many coatings lose gloss when the fruit is wetted (Hall, 1981). Furthermore, gas permeance of many commercial coatings is low, leading to the development of offflavor in citrus fruit, especially after storage at marketing temperatures (Ahmad and Khan, 1987; Cohen et al., 1990; Davis and Hofmann, 1973; Hagenmaier and Shaw, 1992).

The reason for these failures is that no Food and Drug Administration(FDA)-approved material satisfies all requirements. Coatings made with shellac and wood resins give little protection against shrinkage, and tend to fracture, giving the coating a whitish appearance (blush), especially when the fruit is wetted, which often happens when fresh fruit sweats after

Received for publication 29 Nov. 1993. Accepted for publication 10 Nov. 1994. All programs and services of the U.S. Dept. of Agriculture are offered on a nondiscriminatory basis without regard to race, color, national origin, religion, sex, age, marital status, or handicap. Mention of a trademark or proprietary product is for identification only and does not imply a warranty or guarantee of the product by the U.S. Dept. of Agriculture over other products that also may be suitable. The cost of publishing this paper was defrayed in part by the payment of page charges. Under postal regulations, this paper therefore must be hereby marked advertisement solely to indicate this fact. removal from cold storage. Wax coatings give a low shrinkage rate but also low gloss (Hall, 1981). Carbohydrates give low gloss and are susceptible to water damage.

Our objective was to develop betterperforming fruit coatings by using layered coatings, each chosen for what properties it can contribute. In cases where two layers were applied, a wax microemulsison containing hydrocarbons was applied as first layer to form a moisture barrier to prevent weight loss, and a second layer was applied for gloss. In this way, a composite, layered coating was put on the fruit-the goal being to impart some of the properties of each layer in a predictable manner.

\section{Materials and Methods}

In this study, we used Valencia oranges and Marsh grapefruit, harvested from central Florida groves maintained by the Florida Dept. of Agriculture. The fruit were washed with rotating polyethylene brushes, using an 19x dilution of Freshgard 5 (FMC Corp., Lakeland, Fla.), a citrus cleaner containing sodium o-phenyphenate. Coatings were applied by hand within 1 day of harvest. The amount of wet coating applied was determined from the weight of fruit immediately before and after application. In cases where two layers were applied, the first coating was allowed to airdry before applying the second coating - the goal to achieve distinct layers. Creason et al. (1989) applied a second coating when the first was still wet.

Coatings. Wax microemulsions (Table 1) were made as described by Hagenmaier and Baker (1994) or were supplied by Allied Signal (Morristown, N.J.). The oxidized polyethylene was type AC316 and AC680 (Allied Signal) and E20 (Eastman Chemicals, Kingsport, Tenn.). The petroleum wax was type P161 (Exxon, Houston). The resin was an ester of maliec-modified wood resin (Resinall 807A; Resinall Corp., Hattiesburg, Miss.); the shellac was type R-49 (Mantrose-Haeuser Co., Attleboro, Mass.). All ingredients are approved by the FDA for use in citrus coatings. In addition, four shellac and resin-based commercial citrus coatings (Elf Atochem, Monrovia, Calif.; FMC Corp.; Brogdex Co., Pomona, Calif.; and Fresh Mark Corp., Mascotte, Fla.) were used. These water-based coatings are identified in Tables 3 and 5 and Fig. 1 as Commercial 1, 2, 3, and 4, respectively.

Gloss. Measurements were by panel or meter. For panel evaluation, three fruit from each treatment were placed on a numbered tray. Each of nine panelists arranged the trays from highest to lowest gloss; no tray was allowed to be ranked the same as another. The trays were ranked from lowest to highest gloss (1 to 9, respectively). Meter readings are gloss units (GU) measured with a reflectometer (model micro-TRI-gloss; BYK Gardner, Silver Spring, Md.) at a $60^{\circ}$ angle from a line normal to the fruit surface. The reflectometer was calibrated on a standard flat surface, then fitted with a shield having a circular opening (18 $\mathrm{mm}$ in diameter). GU measurements were taken at 10 places on the fruit surface, six fruit per treatment. The 0.82 correlation between panel and reflectometer gloss (Table 2) indicates that the reflectometer readings were a reliable estimate of gloss as perceived by the panelists according to the criteria of Shewfelt (1993). In practice, the panel method was most useful for estimating differences between coatings; the reflectometer provided the only useful method for determining time dependence of gloss.

Table 1. Components of coating formulations. ${ }^{\mathrm{z}}$

\begin{tabular}{|c|c|}
\hline Coating & Nonvolatile components (\% wet wt) \\
\hline$\overline{\text { PE}^{-M C}}$ & $\begin{array}{l}\text { AC680 }(10 \%), \text { BeSquare } 195(7 \%), \\
\text { oleic acid }(3.0 \%)\end{array}$ \\
\hline PE316 & AC316 (17\%), oleic acid $(3.0 \%)$ \\
\hline CCWAX & $\begin{array}{l}\text { Carnauba wax }(9 \%) \text {, Candelilla } \\
\text { wax }(8 \%) \text {, oleic acid }(3.0 \%)\end{array}$ \\
\hline SHELLAC & Shellac (19\%), oleic acid (1.4\%) \\
\hline PE20 & E20 (17\%), oleic acid (3.0\%) \\
\hline SH-RES & $\begin{array}{l}\text { Shellac }(10 \%) \text {, wood resin }(9 \%) \text {, } \\
\text { oleic acid }(1.3 \%)\end{array}$ \\
\hline PE-P161 & $\begin{array}{l}\text { E20 (9\%), P161 (9\%), oleic acid } \\
(3.0 \%)\end{array}$ \\
\hline CAND- $10 \%$ & $\begin{array}{l}\text { Candelilla wax (8.3\%), oleic acid } \\
(1.7 \%)\end{array}$ \\
\hline CAND- $20 \%$ & $\begin{array}{l}\text { Candelilla wax (16.7), oleic acid } \\
(3.3 \%)\end{array}$ \\
\hline
\end{tabular}

${ }^{2}$ All also contained $2 \%$ to $5 \%$ morpholine.

${ }^{y}$ Supplied by Allied Signal, Morristown, N.J.

Table 2. Correlation between gloss by panel and reflectometer.

\begin{tabular}{lcc}
\hline \hline Fruit type & $\mathrm{n}^{\mathrm{z}}$ & $\begin{array}{c}\text { Correlation } \\
\text { coefficient }^{\mathrm{y}}\end{array}$ \\
\hline Marsh grapefruit & 22 & $0.77^{* *}$ \\
Valencia oranges & 13 & $0.80^{* *}$ \\
& 13 & $0.88^{* *}$ \\
\hline
\end{tabular}

${ }^{2}$ Number of coatings tested.

'Between mean values of gloss by panel and meter. ${ }^{* *}$ Significant at $P \leq 0.001$. 
Weight loss. Weight loss was determined by weighing $( \pm 0.1 \mathrm{~g})$ trays of five fruit each, kept at randomized locations in a wellventilated, constant-temperature room. The weight of fruit on each tray was within $20 \%$ of the mean. Except where stated otherwise, storage was at $20 \mathrm{C}$ and $70 \%$ relative humidity (RH). The fruit were weighed over 1 week. Relative weight loss was weight loss of treated fruit as a percentage of the weight loss of the control (washed, uncoated fruit).

Internal gases. Internal gas was withdrawn by syringe from the blossom end, with the fruit submerged in water. Carbon dioxide was determined with a gas chromatograph (model 5890A; Hewlett Packard, Avondale, Pa.) fitted with a $30 \mathrm{~m} \times 0.53-\mathrm{mm}$ (inside diameter) polystyrene GSQ column (JW Scientific, Folsom, Calif.) and a thermal conductivity detector. The column and the detector were at 35 and $120 \mathrm{C}$, respectively; helium carrier gas flow rate was $7 \mathrm{ml} \cdot \mathrm{min}^{-1}$. Oxygen was measured by passing $4 \mathrm{ml}$ of the fruit's internal gas over an $\mathrm{O}_{2}$ electrode (model $507 \mathrm{O}_{2}$; Ingold Electrode, Wilmington, Mass.). Except where stated otherwise, values are for fruit stored 1 week at 20C, five fruit per treatment.

Blush. Coating susceptibility to water damage was visually determined from the appearance of fruit soaked in water overnight (15 to $20 \mathrm{~h}$ ) and then allowed to air-dry 2 to $4 \mathrm{~h}$. Susceptible coatings tended to crack and draw away from the surface, giving the peel a whitish appearance.

Table 3. Properties of coated Marsh grapefruit after 1 week of storage at 20C. ${ }^{2}$

\begin{tabular}{|c|c|c|c|c|c|}
\hline \multicolumn{2}{|c|}{ Coatings } & \multicolumn{3}{|c|}{ Internal $\mathrm{CO}_{2}$} & \multirow[b]{2}{*}{ Blush $^{w}$} \\
\hline $1 \mathrm{st}$ & 2 nd & $\mathrm{RWL}^{\mathrm{y}}$ & $(\%)$ & Gloss $^{x}$ & \\
\hline Control & --- & 100 & 1.8 & 1.1 & None \\
\hline \multirow[t]{2}{*}{ PE-MC } & PE316 & 48 & 3.7 & 4.2 & Negligible \\
\hline & --- & 46 & 4.4 & 1.9 & Negligible \\
\hline PE316 & --- & 85 & 2.0 & 4.2 & None \\
\hline Commercial $1^{\mathrm{v}}$ & --- & 71 & 7.6 & 6.6 & Severe \\
\hline Commercial 2 & --- & 67 & 9.5 & 6.4 & Severe \\
\hline Commercial 3 & --- & 74 & 8.7 & 7.3 & Severe \\
\hline $\operatorname{LSD}_{0.05}$ & & 12 & 3.7 & 1.1 & \\
\hline
\end{tabular}

${ }^{2}$ Mean coating application rate was $0.4 \mathrm{ml}$; mean fruit weight was $370 \mathrm{~g}$.

${ }^{y} \mathrm{RWL}=$ relative weight loss; weight loss as percentage of washed control. Weight loss of control was $2.1 \%$ in 5 days.

${ }^{\mathrm{x}}$ As determined by a panel.

"A panel visually rated blush.

${ }^{\mathrm{v}}$ Commercial 1,2, and 3 are shellac- and resin-containing, high-gloss commercial citrus coatings.

Table 4. Properties of Valencia oranges with single and layered coatings after 1 week of storage at 20C. ${ }^{2}$

\begin{tabular}{|c|c|c|c|c|c|c|c|}
\hline \multicolumn{2}{|c|}{ Coatings } & \multirow[b]{2}{*}{$\mathrm{RWL}^{\mathrm{y}}$} & \multicolumn{2}{|c|}{$\begin{array}{c}\text { Internal gas } \\
(\%)\end{array}$} & \multirow[b]{2}{*}{ Gloss $^{x}$} & \multirow{2}{*}{$\begin{array}{c}\text { Ethanol } \\
\text { (ppm) }\end{array}$} & \multirow[b]{2}{*}{ Blush $^{w}$} \\
\hline $1 \mathrm{st}$ & $2 \mathrm{nd}$ & & $\mathrm{O}_{2}$ & $\overline{\mathrm{CO}_{2}}$ & & & \\
\hline Control & & 100 & 15.0 & 5.4 & 1.0 & 750 & None \\
\hline PE-P161 & --- & 32 & 14.3 & 5.4 & 2.3 & 780 & Negligible \\
\hline PE20 & --- & 49 & 14.2 & 4.9 & 4.7 & 970 & Negligible \\
\hline PE-P161 & PE20 & 26 & 10.2 & 5.7 & 3.2 & 1320 & Mild \\
\hline CCWAX & --- & 32 & 12.4 & 6.1 & 2.2 & 1030 & Negligible \\
\hline SH-RES & --- & 62 & 4.4 & 10.3 & 5.4 & 1450 & Severe \\
\hline PE-P161 & SH-RES & 29 & 6.8 & 9.4 & 7.4 & 1710 & Severe \\
\hline CCWAX & Shellac & 30 & 7.8 & 10.0 & 7.6 & 1670 & Severe \\
\hline $\mathrm{LSD}_{0.05}$ & & 12 & 7.2 & 3.7 & 1.3 & 490 & \\
\hline
\end{tabular}

${ }^{2}$ Mean coating application rate was $0.3 \mathrm{ml}$; mean fruit weight was $200 \mathrm{~g}$.

${ }^{y} \mathrm{RWL}=$ relative weight loss; weight loss as percentage of washed control. Weight loss of control was $3.7 \%$ in 5 days.

${ }^{x}$ As determined by a panel.

${ }^{\text {w} A ~ p a n e l ~ v i s u a l l y ~ r a t e d ~ b l u s h . ~}$
Table 5. Weight loss and internal $\mathrm{CO}_{2}$ of Marsh grapefruit ${ }^{2}$ stored at $23 \mathrm{C}$ and $40 \%$ relative humidity.

\begin{tabular}{|c|c|c|c|}
\hline \multicolumn{2}{|c|}{ Coatings } & \multirow{2}{*}{$\begin{array}{c}\text { Internal } \\
\mathrm{CO}_{2}{ }^{\mathrm{y}} \\
(\%)\end{array}$} & \multirow{2}{*}{$\begin{array}{c}\mathrm{Wt} \\
\operatorname{loss}^{\mathrm{x}} \\
(\mathrm{g})\end{array}$} \\
\hline $\begin{array}{l}\text { First } \\
(\%)\end{array}$ & $\begin{array}{l}\text { Second } \\
\text { (\%/day) }\end{array}$ & & \\
\hline None & --- & $2.9 \mathrm{a}$ & $1.10 \mathrm{a}$ \\
\hline CAND-10\% & --- & $7.3 \mathrm{~b}$ & $0.30 \mathrm{c}$ \\
\hline CAND-20\% & --- & $8.1 \mathrm{~b}$ & $0.27 \mathrm{c}$ \\
\hline GlossCoat-4 & --- & $10.1 \mathrm{c}$ & $0.80 \mathrm{~b}$ \\
\hline CAND-10\% & Commercial 4 & $12.1 \mathrm{~d}$ & $0.37 \mathrm{c}$ \\
\hline CAND-20\% & Commercial 4 & $12.4 \mathrm{~d}$ & $0.29 \mathrm{c}$ \\
\hline
\end{tabular}

${ }^{2}$ Mean coating application rate was $0.4 \mathrm{~g}$ per fruit, and mean fruit weight was $320 \mathrm{~g}$. Weight loss for 1 to 3 days after coating, six samples per treatment, five fruit per sample.

${ }^{y}$ After 6 days of storage and with 25 fruit per treatment.

${ }^{x}$ Mean separation within columns by Tukey's method at $P \leq 0.05$.

These results indicate that fruit gloss was regulated more by the second than the first layer of coating. Fruit coated with the hydrocarbon-containing microemulsions had low gloss. Fruit coated with polyethylene wax had intermediate gloss, whether applied as the only or the second coat. The fruit with highest gloss had a shellac or a resin ester outer-layer coating, or a high-gloss commercial coating formulation containing shellac and resin (Tables 3 and 4).

Values of internal $\mathrm{CO}_{2}$ and $\mathrm{O}_{2}$ were most like uncoated control for fruit with wax coatings, whether or not these coatings contained hydrocarbons or were applied in one coat or two (Tables 3-5). This result reflects the higher permeability to $\mathrm{CO}_{2}$ and $\mathrm{O}_{2}$ of such coatings (Hagenmaier and Shaw, 1992). Internal gases were most different from control for shellac and resin coatings; these coatings have low permeability to $\mathrm{O}_{2}$ and $\mathrm{CO}_{2}$ and also tend to block pores (Hagenmaier and Baker, 1993c). Because shellac and resin inhibit gas exchange, fruit with these coatings tend to have high ethanol content (Table 4).

Coating fracture that resulted in blush or whitening was highest for coatings made of shellac and wood resin (Tables 3 and 4). Although the test used was severe, it may indicate which coatings would suffer most in appearance from the condensation that forms on fruit after removal from cold storage.

An unexpected advantage of using layered coatings was gloss preservation (Fig. 1). Gloss decreased more slowly for fruit coated with a hydrocarbon-containing wax (PE-P161) than for fruit coated only with a high-gloss coating (GlossCoat 5). The rather stressful storage conditions used in this case (29C and 60\% RH) caused rapid weight loss (1\% per day for fruit with only the high-gloss coating). In practice, little citrus fruit is held under such conditions, except perhaps fruit marketed at roadside stands or kept in a fruit bowl at home. Fruit stored under conditions that cause less weight loss may give different results.

A disadvantage with the layered coatings was restricted gas exchange from the fruit skin. According to theory, the resistance to gas permeation of a composite coating equals the sum of the resistances of the separate layers 
(Crank, 1956). Thus, water vapor resistance always should be higher (weight loss of fruit should be lower) for a composite coating than for either coating by itself. However, weight loss of fruit with layered coatings was generally higher than for fruit with only a wax coating (Tables 3-5). In two packinghouse trials with candelilla wax and high-gloss commercial coating, the mean weight loss was $30 \%$ higher for fruit with layered coatings than for fruit coated only with wax (data not shown).
One possible explanation is that the first coating was partially removed by applying the second coat; this seems more likely in a packinghouse situation because of the abrasion that occurs as the second coating is brushed on. However, the internal $\mathrm{CO}_{2}$ was higher for fruit with two coatings (Table 5) than with either coating alone, which would not seem likely if the first coating had been partially removed.

Whatever the explanation, not all layered coatings were equally successful for citrus.

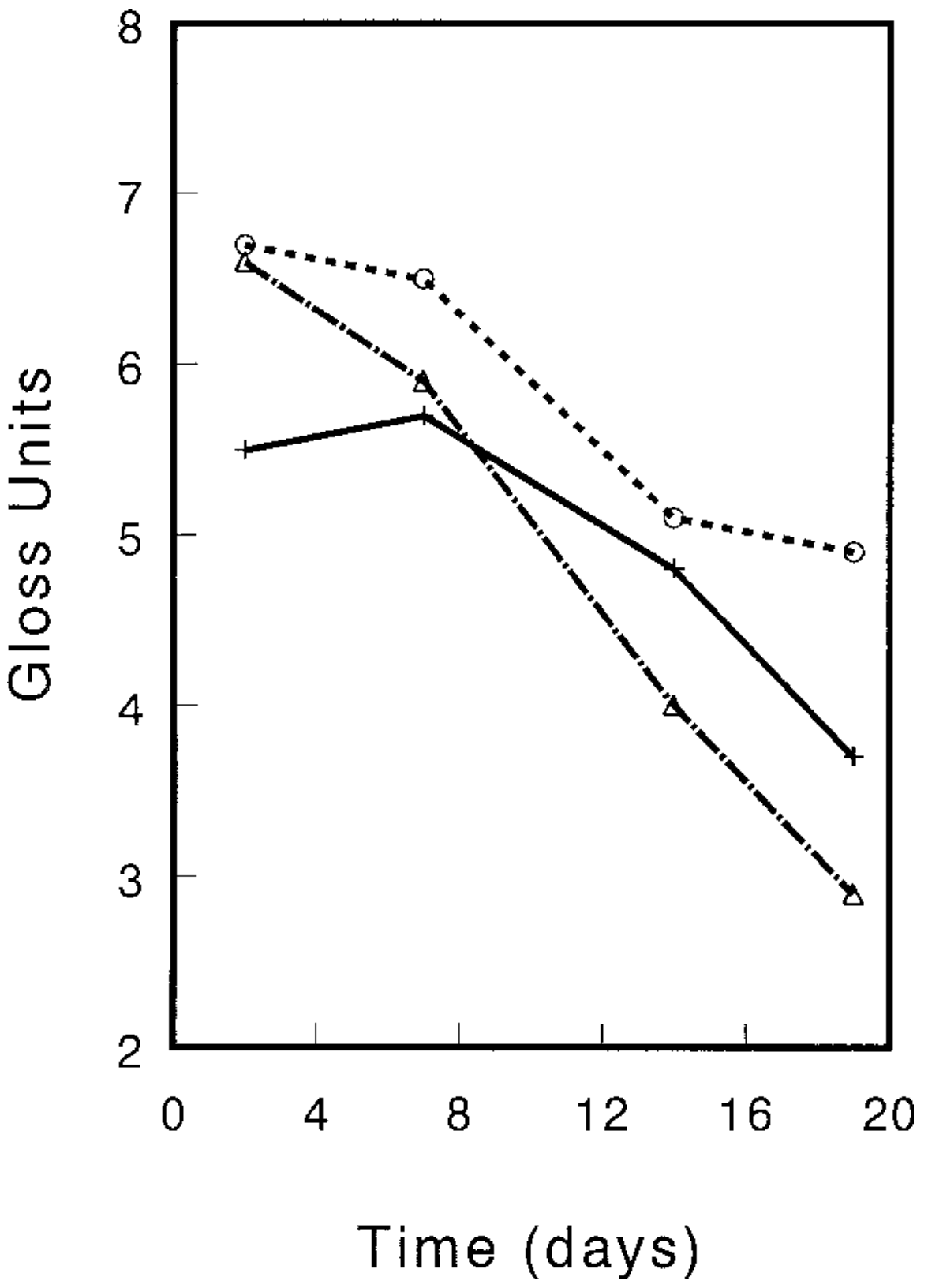

Fig. 1. Gloss of Valencia oranges with PE-P161, Commercial 2, or layers of both.

Fruit coated first with wax and then with shellac or resin resulted in overly restricted gas exchange. Although the wax layer by itself had much lower resistance to $\mathrm{O}_{2}$ and $\mathrm{CO}_{2}$ permeation than the high-gloss coating, the combination-for reasons not understoodhad sufficiently high barrier to gas exchange that shelf stability would be threatened. However, coating citrus fruit first with a moisturebarrier wax and then with a more glossy wax did not overly restrict gas exchange of citrus fruit (Tables 3 and 4) (Hagenmaier and Baker, 1993b).

\section{Literature Cited}

Ahmad, M. and I. Khan. 1987. Effect of waxing and cellophane lining on chemical quality indices of citrus fruit. Plant Foods for Human Nutrition 37:47-57.

Ben-Yehoshua, S. 1967. Some physiological effects of various skin coatings on orange fruit. Israel J. Agr. 17(1):17-27.

Cohen E., Y. Shalom, and I. Rosenberger. 1990. Postharvest ethanol buildup and off-flavor in 'Murcott' tangerine fruits. J. Amer. Soc. Hort. Sci. 115:775-778.

Crank, M. 1956. The mathematics of diffusion. Oxford Univ. Press, London.

Creason, K.C., J.A. Fillmore, S.P. Salka, and R.R. Holland. 1989. R.R. Fruit waxing method, p. 18. U.S. Patent $4,842,880$.

Davis, P.L. and R.C. Hofmann. 1973. Effects of coatings on weight loss and ethanol buildup in juice of oranges. J. Agr. Food Chem. 21:455-458.

Hagenmaier, R.D. and R.A. Baker. 1993a. Cleaning method affects shrinkage rate of citrus fruit. HortScience 28:824-825.

Hagenmaier, R.D. and R.A. Baker. 1993b. Citrus fruit with single or layered coatings compared with packinghouse-coated fruit. Proc. Fla. State Hort. Soc. 106:238-240.

Hagenmaier, R.D. and R.A. Baker. 1993c. Reduction in gas exchange of citrus fruit by wax coatings. J. Agr. Food Chem. 41:283-286.

Hagenmaier, R.D. and R.A. Baker. 1994. Wax microemulsions and emulsions as citrus coatings. J. Agr. Food Chem. 42:899-902.

Hagenmaier, R.D. and P.E. Shaw. 1992. Gas permeability of fruit coating waxes. J. Amer. Soc. Hort. Sci. 117:105-109.

Hall, D.J. 1981. Innovations in citrus waxing-An overview. Proc. Fla. State Hort. Soc. 94:258-263.

Kaplan, J.J. 1986. Washing, waxing and coloradding, p. 379-395. In: W.F. Wardowski, S. Nagy, and W. Grierson (eds.). Fresh citrus fruits. AVI, Westport, Conn.

Namesny, C. and A. Pablo. 1988. Evaluation of commercial citrus waxes, p. 1505-1510. R. Goren and K. Mendel (eds.). Citriculture. Proc. 6th Intl. Citrus Congr., Tel Aviv, Israel, 6-11 Mar. 1988.

Shewfelt, R.L. 1993. Measuring quality and maturity, p. 99-124. In: R.L. Shewfelt andS.E. Prussia (eds.). Postharvest handling, A systems approach. Academic, San Diego. 